\title{
Influence of Random Track Irregularities on Dynamic Response of Bridge/Track Structure/High-Speed Train Systems
}

\author{
Marian Klasztorny ${ }^{1}$ and Monika Podworna ${ }^{2}$ \\ 1. Department of Mechanics and Applied Computer Science, Faculty of Mechanical Engineering, Military University of Technology, \\ Warsaw 00-908, Poland \\ 2. Department of Dynamics of Structures, Faculty of Civil Engineering, Wroclaw University of Technology, Wroclaw 50-370, Poland
}

\begin{abstract}
Random vertical track irregularities are one of essential vibration sources in bridge, track structure and high-speed train systems. The common model of such irregularities is a stationary and ergodic Gaussian process. The study presents the results of numerical dynamic analysis of advanced virtual models of composite BTT (bridge/ballasted track structure/high-speed train) systems. The analysis has been conducted for a series of types of single-span simply-supported railway composite (steel-concrete) bridges, with a symmetric platform, located on lines with ballasted track structure adapted for high-speed trains. The bridges are designed according to Polish bridge standards. A new methodology of numerical modeling and simulation of dynamic processes in BTT systems has been applied. The methodology takes into consideration viscoelastic suspensions of rail-vehicles, nonlinear Hertz wheel-rail contact stiffness and one-side wheel-rail contact, physically nonlinear elastic-damping properties of the track structure, random vertical track irregularities, approach slabs and other features. Computer algorithms of FE (finite element) modeling and simulation were programmed in Delphi. Both static and dynamic numerical investigations of the bridges forming the series of types have been carried out. It has been proved that in the case of common structural solutions of bridges and ballasted track structures, it is necessary to put certain limitations on operating speeds, macadam ballast and vertical track roughness.
\end{abstract}

Key words: Steel-concrete composite bridge, ballasted track structure, high-speed passenger train, random vertical track irregularities, numerical analysis.

\section{Introduction}

Composite (steel-concrete) bridges loaded by high-speed trains need to be designed or modernized to ensure the SC (serviceability condition), the DC (durability condition), the TSC (traffic safety condition) and the PCC (passenger comfort condition). Nowadays, each railway bridge is designed individually. Railway track irregularities are considered to be one of the main factors affecting dynamic response of a composite BTT (bridge/ballasted track structure/high speed train system). The irregularities are due to track formation technology, contemporary mechanical maintenance,

Corresponding author: Marian Klasztorny, Ph.D., professor, research fields: dynamics of bridges and mechanics of composites. E-mail: m.klasztorny@gmail.com. soil settlement and other factors. Experimental measurements and/or modeling of track irregularities are considered in a number of papers, e.g., Refs. [1-3]. The common model of railway track roughness vertical profiles is a stationary and ergodic Gaussian process in space. The profile is characterized by a one-sided PSD (power spectral density) function. The PSD function corresponding to line grades 1 to 6 from American Railway Standard was elaborated by USA FRA (Federal Railroad Administration).

Review of state-of-the-art till 2004 in dynamics of railway bridges under high-speed trains is presented in Ref. [4]. Literature review on dynamics of railway bridges loaded by high-speed trains over the last decade is presented in Ref. [5]. The most important 
contributions are shortly described below.

$\mathrm{Au}$ et al. [6] analyze a railway cable-stayed bridge with a total length of $750 \mathrm{~m}$, subjected to a moving train. They adopted a planar model and FEM (finite element mothod) discretization of the bar bridge superstructure. The basic model of a moving vehicle supported on two two-axle bogies is the Matsuura model with 6DOF (6 degrees of freedom). The method of explicit formulation of the equations of motion in matrix notation is applied. Zhang et al. [7] model the 3D BTT system using bar finite elements to discretize the bridge superstructure and rails. The track structure is reflected by the Winkler foundation. A rail-vehicle is a multibody system with viscoelastic suspensions, both horizontal and vertical, of the first and second stage. Wheels are treated as sprung masses, according to the Hertz theory.

Au et al. [3] have developed an 1D vibration study on railway cable-stayed bridges under moving trains, taking into account random rail irregularities. The main girder of the bridge is modeled using 6DOF Euler beam finite elements and taking into account the linear and geometric stiffness matrices. Double-side constraints between the moving wheel set unsprung masses and the rails are assumed. The track structure is neglected. The matrix equation of motion of the bridge/moving train system is formulated in the explicit form. Sample vertical profiles of random rail roughness, considered as stationary and ergodic processes in space, are generated using the empirical formula for PSD function with the parameters corresponding to the USA Quality Classes 1-6.

Podworna [8, 9] developed an 1D theory of modeling BTT systems. The bridge superstructure is modeled as a step-wise prismatic viscoelastic Timoshenko beam. The rails are mapped by a continuous viscoelastic prismatic Euler beam. Fasteners and ballast-bed are physically nonlinear and sleepers are point masses vibrating vertically. The track bed (subsoil) is reflected by a set of equidistant single mass viscoelastic oscillators. The train is composed of vehicles each modeled by a 6DOF Matsuura system. Dynamic response of an existing bridge subjected to different moving trains is developed in Ref. [10], including track irregularities and neglecting snaking of wheel sets. The research was carried out using the 3D DBTI (dynamic bridge-train interaction) model, in which the inertia forces of the moving unsprung train axles are coupled with the bridge.

Summing up, to-date theoretical studies on the effect of random vertical track irregularities on vibrations of a railway bridge loaded by a high-speed train were performed on $1 \mathrm{D} / 3 \mathrm{D}$ simplified models of the BTT system.

The study presents the results of numerical dynamic analysis of advanced virtual models of composite bridge/ballasted track structure/high-speed train systems. The analysis has been conducted for a series-of-types of single-span simply-supported railway composite (steel-concrete) bridges, with a symmetric platform, located on lines with ballasted track structure adapted for high-speed trains. The bridges are designed according to Polish Bridge Standards [11, 12]. The full description of bridge series-of-types design is presented in Ref. [13]. A new methodology of numerical modeling and simulation of dynamic processes in BTT systems, developed by Podworna and Klasztorny [5], has been applied. This methodology takes into consideration viscoelastic suspensions of rail-vehicles, nonlinear Hertz wheel-rail contact stiffness and one-side wheel-rail contact, physically nonlinear elastic-damping properties of the track structure, random vertical track irregularities, approach slabs and other features. Computer algorithms of FE modeling and simulation were programmed in Delphi. Both static and dynamic numerical investigations of the bridges forming the series-of-types have been carried out. It has been proved that in the case of common structural solutions of bridges and ballasted track structures, it is necessary to put certain limitations on operating speeds, macadam ballast and vertical track roughness. 


\section{Description of Series-of-Types of Railway Bridges}

A series-of-types of railway composite SCB (steel-concrete bridges) has been designed according to Polish Standards [11, 12], under the following assumptions:

- Bridges/viaducts are located on the main railways of classification coefficient $k=+2$;

- Axis of an unloaded railway track is rectilinear and horizontal;

- Track gauge is adapted for high-speed trains and is equal to $5.10 \mathrm{~m}$;

- Bridges have the composite (steel-concrete) superstructure and separate spans for each track;

- Spans are simply supported.

A detailed description of the design process and the results is presented in Ref. [13]. The bridge series-of-types composes of five objects of codes and basic geometric parameters set up in Table 1, where $L$-theoretical span length, $L_{T}$ - total span length, $H$-structural height.

Construction of the bridge-track system is illustrated with a case of SCB-18 bridge in Figs. 1 and 2 . Cross-sections of the remaining bridges are analogous, only the web and lower chords of the main beams as well as the vertical brackets are subjected to respective changes. New structural features of bridges forming the SCB series-of-types are as follows:

Table 1 Codes and basic geometric parameters of bridges forming SCB series-of-types.

\begin{tabular}{llllll}
\hline $\begin{array}{l}\text { Bridge } \\
\text { code }\end{array}$ & SCB-15 & SCB-18 & SCB-21 & SCB-24 & SCB-27 \\
\hline$L(\mathrm{~m})$ & 15.00 & 18.00 & 21.00 & 24.00 & 27.00 \\
$L_{T}(\mathrm{~m})$ & 15.80 & 18.80 & 21.80 & 24.80 & 27.80 \\
$H(\mathrm{~m})$ & 1.82 & 1.97 & 2.12 & 2.27 & 2.42 \\
\hline
\end{tabular}

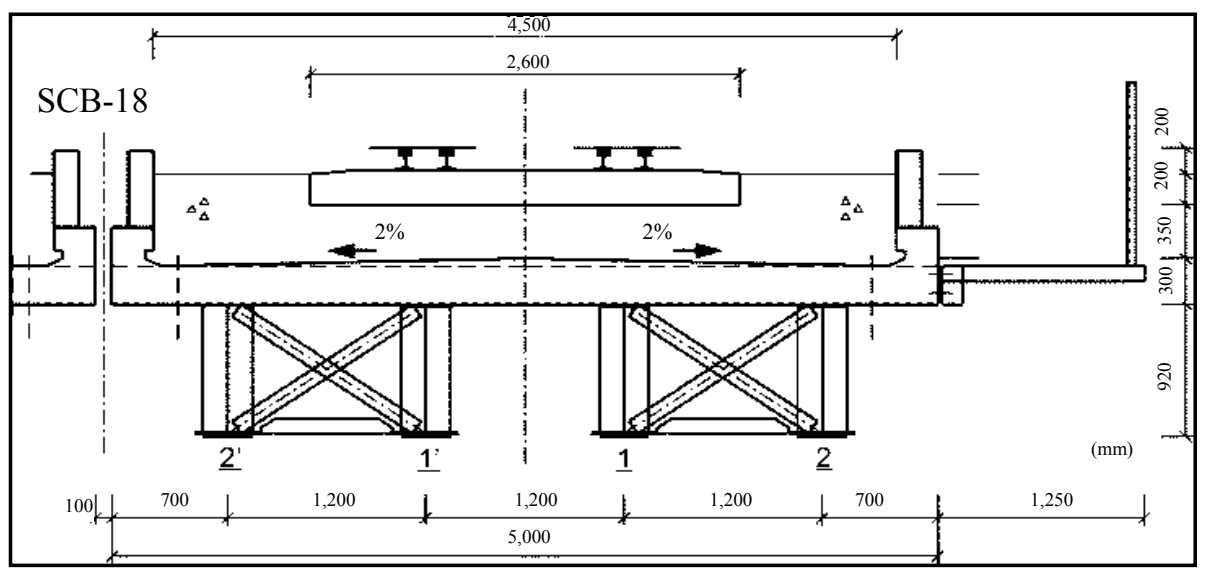

Fig. 1 Cross-section of SCB-18 bridge at midspan.

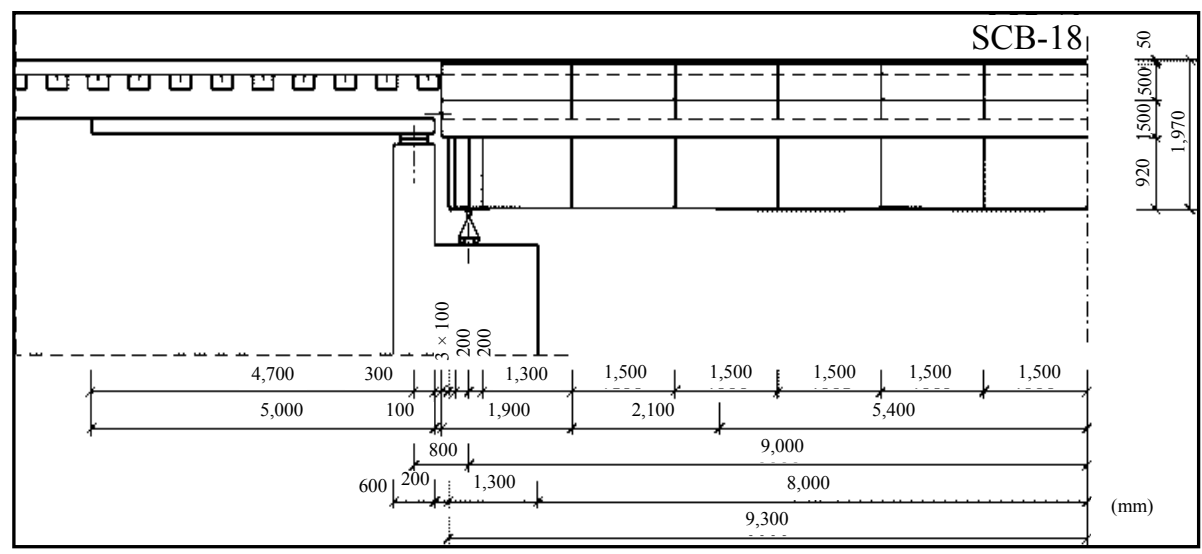

Fig. 2 Longitudinal section of symmetric SCB-18 bridge and of transient zone part. 
- full symmetric RC (reinforced concrete) platform (minimization of flexural-torsional vibrations, elimination of vibration coupling of parallel neighboring spans through the ballast);

- structurally reinforced low concrete kerbs of the platform plate, with application of technological stop and dilatations (elimination of a one-side RC wall inducing asymmetric vibrations of the span and increase in lateral and flexural-torsional vibrations);

- shell CFRP (carbon fiber-reinforced plastic) composite shields (resistant to vibrations) fixed to the kerbstones with steel anchors, with vertical dilatations (1 cm width, $1.49 \mathrm{~m}$ distance), sustaining the ballast between the kerbstones and decreasing the platform mass;

- four main steel I-beams joined in pairs, with the use of vertical and horizontal brackets, with no brackets between the beam pairs;

- bearings unmovable transversally under each inner beam (better transfer of the horizontal loads on the main beams);

- approach slabs applied and supported with elastomeric bearings and produced of B35 concrete, reinforced with AII/18G2-B steel;

- back walls of the bridgeheads with increased thickness in order to support the approach slabs with elastomeric bearings.

There is applied $150 \mathrm{~kg} / \mathrm{m}^{3}$ cement-stabilized soil in the approach zones. The track structure is composed of continuously welded S60 main rails, S60 side rails of length covering the bridge span and the approach slabs, B320 U60, B320 U60-U PC (prestressed concrete) sleepers, first class crushed stone ballast to the depth of $35 \mathrm{~cm}$ under a sleeper in the track axis and Vossloh 300-1 fasteners of the main and side rails. Approach slabs are designed to minimize the threshold effect, to eliminate a jump in subsidence of the ground in the area of the bridgehead and to increase durability of the track in the bridgehead area. Each transient zone contains: a cement-stabilized soil zone, nonwovens reinforced embankment ground, a sand-gravel mix layer under the ballast and an approach slab.

The following construction technology of composite girders was adopted:

- assembly on the stiff scaffolding (the composite superstructure operates only in Phase II, i.e., after platform-beams coupling and concrete curing);

- no initial stresses incorporated in steel beams before their connection to the RC platform plate.

The engineering calculations were performed under the following main assumptions:

- The composite cross-section operates in a linear-elastic range;

- Steel beams-concrete platform connection is non-deformable;

- A composite cross-section is reduced to the equivalent steel cross-section;

- Dimensioning is performed for elastic ultimate limit states (stresses resulting from design loads not exceeding design strength);

- Dimensioning is performed for limit states (displacements/vibrations induced by characteristic loads not exceeding displacement limits).

The design is conducted in accordance to detailed design rules presented in Ref. [14] and takes into account the following stresses:

- stresses induced by dead loads;

- stresses induced by vertical live loads;

- stresses induced by rheological effects.

This is the basic load system (P) [11]. The limit states include:

- check the SC condition for deflection of a composite girder under moving load;

- check the DC condition taking into account high-cycle fatigue;

- check the PCC condition;

- check the TSC condition in the scope of vertical vibrations of a bridge.

Table 2 collects values of geometric, mass and stiffness parameters of SCB series-of-types bridges, used in numerical analysis of BTT systems [15]. Table 2 includes the following quantities: 
Table 2 Parameters of bridges forming SCB series-of-types.

\begin{tabular}{lllllll}
\hline Parameter & Unit & SCB-15 & SCB-18 & SCB-21 & SCB-24 & SCB-27 \\
\hline$L$ & $\mathrm{~m}$ & 15.00 & 18.00 & 21.00 & 24.00 & 27.00 \\
$h_{b}(0.5 L)$ & $\mathrm{mm}$ & 735 & 858 & 1,009 & 1,156 & 1,342 \\
$h_{t}(0.5 L)$ & $\mathrm{mm}$ & 441 & 518 & 617 & 720 & 834 \\
$I(0.5 L)$ & $\mathrm{m}^{4}$ & 0.067789 & 0.101580 & 0.154680 & 0.221439 & 0.311789 \\
$W_{b}(0.5 L)$ & $\mathrm{m}^{3}$ & 0.092242 & 0.118366 & 0.153232 & 0.191603 & 0.232258 \\
$W_{t}(0.5 L)$ & $\mathrm{m}^{3}$ & 0.153681 & 0.196170 & 0.250882 & 0.307435 & 0.374040 \\
$E I(0.5 L)$ & $\mathrm{Nm}^{2}$ & $13.897 \times 10^{9}$ & $20.824 \times 10^{9}$ & $31.710 \times 10^{9}$ & $45.395 \times 10^{9}$ & $63.917 \times 10^{9}$ \\
$I(0)$ & $\mathrm{m}^{4}$ & 0.050188 & 0.075905 & 0.116859 & 0.168889 & 0.240933 \\
$E I(0)$ & $\mathrm{Nm}^{2}$ & $10.289 \times 10^{9}$ & $15.561 \times 10^{9}$ & $23.956 \times 10^{9}$ & $34.622 \times 10^{9}$ & $49.391 \times 10^{9}$ \\
$m(0.5 L)$ & $\mathrm{kg} / \mathrm{m}$ & 5,300 & 5,470 & 5,660 & 5,850 & 6,020 \\
$m(0)$ & $\mathrm{kg} / \mathrm{m}$ & 5,050 & 5,210 & 5,380 & 5,550 & 5,710 \\
$\gamma$ & - & 0.01125 & 0.0075 & 0.005 & 0.005 & 0.005 \\
\hline
\end{tabular}

- $h_{b}(0.5 L), h_{t}(0.5 L)$ - vertical distances to bottom and top fibres, measured from mass centre of equivalent cross-section of bridge superstructure, at midspan;

- $I(0.5 L)$ - geometrical moment of inertia in respect to horizontal central axis of equivalent cross-section of bridge superstructure at midspan;

- $W_{b}(0.5 L), W_{t}(0.5 L)$ - bending rates for bottom and top fibres of equivalent cross-section of bridge superstructure at midspan;

- $E I(0.5 L)$-flexural stiffness of equivalent cross-section of bridge superstructure at midspan;

- $m(0.5 L)$ - mass per unit length of equivalent cross-section of bridge superstructure at midspan (with isolation layer, levelling concrete, kerbs, covers, sidewalk, joints, ribs and brackets taken into account);

- $I(0), E I(0), m(0)$ — selected geometric, stiffness and mass parameters of equivalent cross-section of bridge superstructure, at support area (without overlay of lower chord of main beams);

- $\gamma$-Rayleigh damping ratio of bridge superstructure.

A vibration frequency range in which damping is approximately constant is assumed as $1 \mathrm{~Hz}$ to $500 \mathrm{~Hz}$.

Subsequent physical parameters occurring in numerical modeling of BTT systems have the following values [15]: $\rho_{b}=2,000 \mathrm{~kg} / \mathrm{m}^{3}$-ballast density, $m_{r}, m_{s r}=120 \mathrm{~kg} / \mathrm{m}, M_{s}=366 \mathrm{~kg}, M_{b}=$ $2,900 \mathrm{~kg}, m_{a}=2,000 \mathrm{~kg} / \mathrm{m}, L_{a}=4.8 \mathrm{~m}, 2 D=204$ $\mathrm{m}$, where: $m_{r}$-mass of main rails per unit length, $m_{s r}$ - mass of side rails per unit length, $M_{s}$ - mass of one sleeper (with two fasteners), $M_{b}$-mass of ballast per one sleeper, $m_{a}$-mass of approach slab per unit length, $L_{a}$-length of approach slab, $2 D$-length of out-of-approach zone.

\section{Description of Mathematical and Numerical Modelling and Simulation of BTT Systems}

A theory of advanced 1D physical and mathematical modeling of a composite (steel-concrete) bridge/ballasted track structure/high-speed train system is developed by authors in Ref. [5]. The system is composed of a simply supported composite bridge span, two approach slabs, a ballasted track structure adapted to high operating speeds and a high-speed train. In the physical and numerical modeling of this system, the following main assumptions are adopted:

- There is considered a finitely long deformable track with continuously welded rails including the out-of-transition zones, the transition zones and the bridge zone. The track outside of these zones is non-deformable and straight;

- The track axis is a horizontal straight line. There are random vertical track irregularities resulting from construction and maintenance of the track, as well as settlement of ballast and subgrade. Random vertical track irregularities are identical for both main rails; 
- The BTT system has a vertical plane of symmetry coinciding with the track axis: this is the plane of vibration. There are only vibrations in this plane, commonly termed as vertical vibrations;

- Operating and side rails are viscoelastic prismatic beams deformable in flexure;

- Rail-sleeper fasteners are viscoelastic elements with the non-linear elastic characteristic;

- Sleepers vibrate vertically and are modeled as concentrated masses;

- Macadam ballast is modeled as a set of vertical viscoelastic constraints with the non-linear elastic characteristic. The model includes the possibility of detachment of the sleepers from the ballast. The lumped ballast model is used. Each sleeper is supported viscoelastically;

- Track bed (subsoil) is a linearly viscoelastic layer modeled discretely;

- Approach slabs are modeled as viscoelastic prismatic beams deformable in flexure. Each slab is supported on one edge on the abutment. The slab material is viscoelastic;

- The bridge superstructure is reflected by a simply-supported stepwise prismatic beam, deformable in flexure, symmetrical relative to the bridge midspan. The superstructure materials (steel, concrete) are viscoelastic;

- A cross-section of the bridge superstructure and the platform is symmetrical about the vertical axis. Vibration coupling of twin spans over the ballast does not occur;

- Connections of the reinforced concrete slab with the main steel beams are non-deformable;

- Rail-vehicles form a high-speed ICE-3 German train. Each vehicle has two independent two-axle bogies. The planar Matsuura model of a rail-vehicle is developed via incorporating non-linear one-sided contact Hertz springs at wheel set-rail contacts. Micro separations and impacts of moving wheel sets in reference to the main rails are taken into consideration;

- The train operating velocity is constant and belongs to the interval $30-300 \mathrm{~km} / \mathrm{h}$. Velocity $30 \mathrm{~km} / \mathrm{h}$ is treated as corresponding to the quasi-static passage of the train;

- Vibrations of the BTT system are physically nonlinear and geometrically linear.

Compared to the state-of-the-art, the 1D physical model developed in Ref. [5] is the most advanced and is expected to produce dynamic processes close to reality. The BTT system is composed of the following inertial subsystems (Figs. 3 and 4): BS-bridge superstructure, LAS - left approach slab, RAS — right approach slab, LB-left ballast-bed, RB-right ballast-bed, SL-sleepers, OR-operating rails, SR-side rails, $\quad R V i(i=1,2, \ldots), \quad N_{v}$-railway vehicles. These subsystems are subject to the relevant subsets of vertical interaction forces, carried by elastic/viscoelastic, physically linear/nonlinear constraints. Using Lagrange's equations and the internal assembling, linear matrix equations of motion of individual subsystems are obtained with the generalized load vectors stored in an implicit form. Linear/non-linear interaction forces are transformed

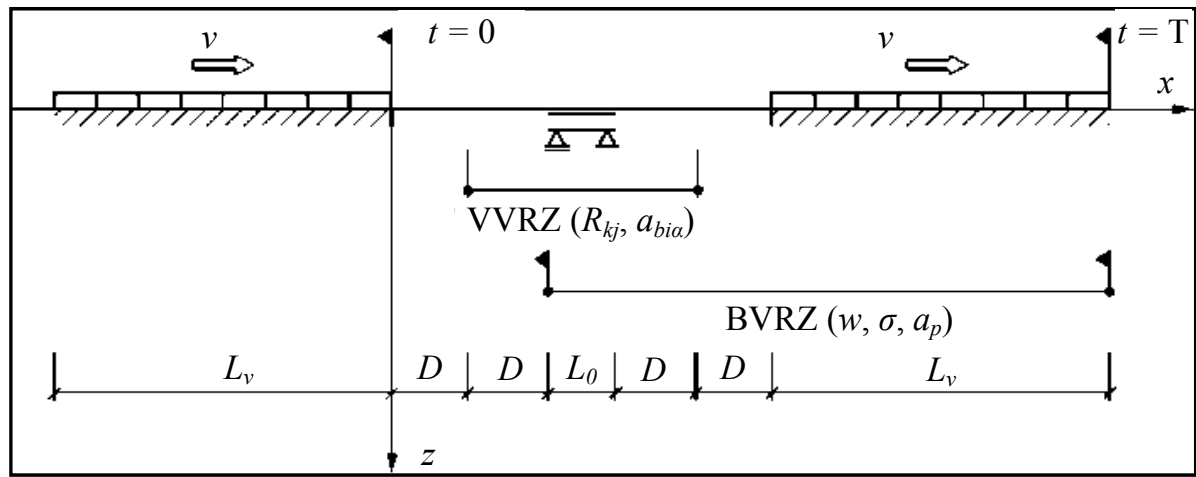

Fig. 3 Schematic diagram of BTT system at time $t=0$ and $t=$ T. 


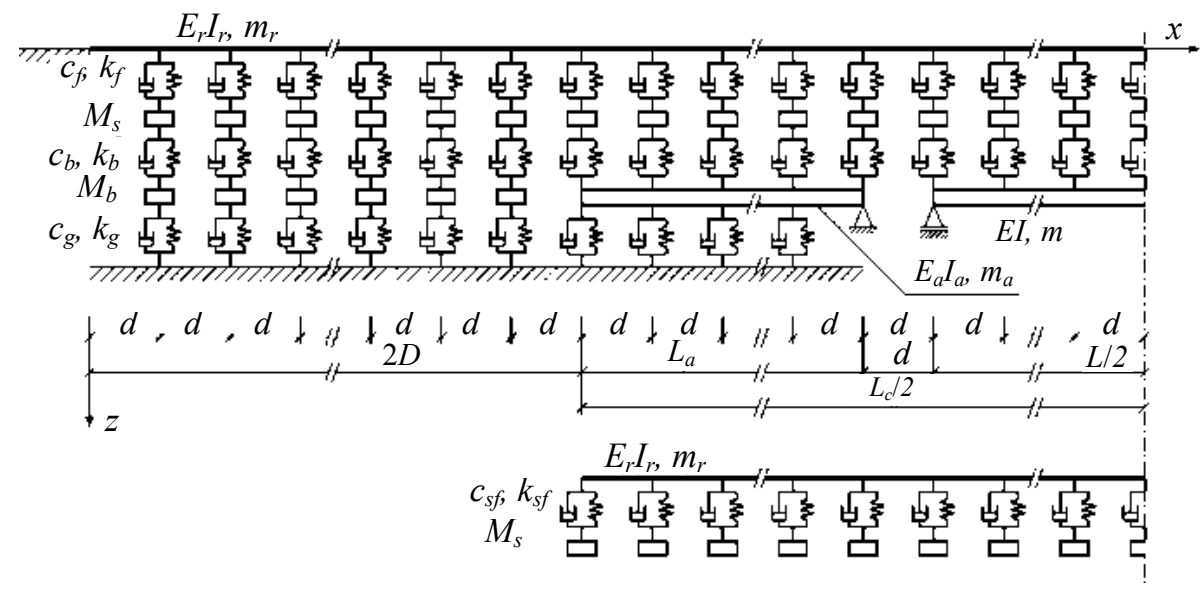

Fig. 4 1D physical model of track structure/bridge subsystem.

into the generalized load vectors. This formulation leads to equations of motion of the subsystems with constant coefficients. Coupling and non-linearity of the subsystems are hidden in the generalized load vectors expressed in terms of the interaction forces. Symbols marked in Figs. 3 and 4 have the following meanings:

VVRZ (vehicle vibration registration zone) — area of registration of design quantities found in TSC and PCC conditions;

BVRZ (bridge vibration registration zone) - area of registration of vibrations and stresses in reference to bridge superstructure and platform;

$L_{o}$-bridge span length plus length of approach slabs plus two sleeper intervals;

$L_{v}$ - train set length;

$v$-operating velocity (horizontal velocity of moving load);

$t$-time variable;

$x, y$ - coordinates of planar system;

$T$-dynamic process duration time;

$E I(x), m(x)$-flexural stiffness and mass per unit length of bridge superstructure;

$E I_{r}, m_{r}$-flexural stiffness and mass per unit length of rails;

$E_{a} I_{a}, m_{a}$-flexural stiffness and mass per unit length of approach slabs;

$M_{s}, d$-mass and spacing of sleepers;

$M_{b}$ —point mass reflecting ballast mass over distance $d$; $c_{f}, k_{f}, c_{s f}, k_{s f}, c_{b}, k_{b}, c_{g}, k_{g}$-partly nonlinear damping and stiffness coefficients in reference to main rails, side rails, ballast and track subsoil.

The remaining symbols are explained in further considerations.

A 1D physical model of the track structure/bridge subsystem is presented in Fig. 4. A constant sleeper spacing $d$ is used to discretise the subsystem. The main rails are fixed at the ends of the finite-long section of the track, $4 D+L_{o}$. The side rails are of length of $L_{o}$ and are rested viscoelastically on the sleepers. Viscoelastic elements modeling fasteners and ballast incorporate physically nonlinear elastic constraints. Discretization of beams modeling operating rails, side rails, approach slabs and the bridge superstructure uses classic beam finite elements deformed in flexure, with 4DOF and length $d$. Nodes of the finite elements coincide with the positions of the sleepers [5].

Transient and quasi-steady-state vibrations of the BTT system are governed by $8+N_{v}$ matrix equations of motion in the following implicit form [5]:

$$
\begin{gathered}
\boldsymbol{B} \ddot{\boldsymbol{q}}+\boldsymbol{C} \dot{\boldsymbol{q}}+\boldsymbol{K \boldsymbol { q }}=\boldsymbol{F} \\
\boldsymbol{B}_{l a} \ddot{\boldsymbol{q}}_{l a}+\boldsymbol{C}_{l a} \dot{\boldsymbol{q}}_{l a}+\boldsymbol{K}_{l a} \boldsymbol{q}_{l a}=\boldsymbol{F}_{l a} \\
\boldsymbol{B}_{r a} \ddot{\boldsymbol{q}}_{r a}+\boldsymbol{C}_{r a} \dot{\boldsymbol{q}}_{r a}+\boldsymbol{K}_{r a} \boldsymbol{q}_{r a}=\boldsymbol{F}_{r a} \\
\left\{\boldsymbol{M}_{b}\right\} \ddot{\boldsymbol{q}}_{l b}=\boldsymbol{F}_{l b} \\
\left\{\boldsymbol{M}_{b}\right\} \ddot{\boldsymbol{q}}_{r b}=\boldsymbol{F}_{r b} \\
\left\{\boldsymbol{M}_{s}\right\} \ddot{\boldsymbol{q}}_{s}=\boldsymbol{R}_{f}-\boldsymbol{R}_{b} \\
\boldsymbol{B}_{r} \ddot{\boldsymbol{q}}_{r}+\boldsymbol{C}_{r} \dot{\boldsymbol{q}}_{r}+\boldsymbol{K}_{r} \boldsymbol{q}_{r}=\boldsymbol{F}_{r} \\
\boldsymbol{B}_{s r} \ddot{\boldsymbol{q}}_{s r}+\boldsymbol{C}_{s r} \dot{\boldsymbol{q}}_{s r}+\boldsymbol{K}_{s r} \boldsymbol{q}_{s r}=\boldsymbol{F}_{s r} \\
\boldsymbol{B}_{i} \ddot{\boldsymbol{q}}_{i}=\boldsymbol{F}_{i}, i=1,2, \ldots, N_{v}
\end{gathered}
$$


where, $\boldsymbol{q}(t), \boldsymbol{q}_{l a}(t), \boldsymbol{q}_{r a}(t), \boldsymbol{q}_{l b}(t), \boldsymbol{q}_{r b}(t), \boldsymbol{q}_{s}(t)$, $\boldsymbol{q}_{r}(t), \boldsymbol{q}_{s r}(t)$-vectors of generalized coordinates for BS, LAS, RAS, LB, RB, SL, OR and SR subsystems, respectively, $\quad \boldsymbol{q}_{i}(t), i=1,2, \ldots, N_{v}$-vectors of generalised coordinates for subsequent rail-vehicles, $\boldsymbol{B}, \boldsymbol{C}, \boldsymbol{K}-$ mass, damping and stiffness matrices for BS subsystem, respectively, $\boldsymbol{B}_{l a}, \boldsymbol{C}_{l a}, \boldsymbol{K}_{l a}, \boldsymbol{B}_{r a}, \boldsymbol{C}_{r a}$, $\boldsymbol{K}_{r a}$ - mass, damping and stiffness matrices for LAS and RAS subsystems, respectively, $\left\{\boldsymbol{M}_{b}\right\}$-mass matrix for LB and RB subsystems, $\left\{\boldsymbol{M}_{s}\right\}$-mass matrix for SL subsystem, $\boldsymbol{B}_{r}, \boldsymbol{C}_{r}, \boldsymbol{K}_{r}, \boldsymbol{B}_{s r}, \boldsymbol{C}_{s r}, \boldsymbol{K}_{s r}$-mass, damping and stiffness matrices for OR and SR subsystems, respectively, $\boldsymbol{B}_{i}$ - mass matrix for $i$ th rail-vehicle, $\boldsymbol{R}_{f}, \boldsymbol{R}_{s f}$-vectors of interaction forces transmitted by fasteners in OR and SR subsystems, respectively, $\boldsymbol{R}_{b}$-vector of interaction forces transmitted by ballast-bed, $\boldsymbol{R}_{g}$ - vector of interaction forces transmitted by track-bed, $\boldsymbol{R}_{w i}$-vector of moving pressure forces of $i$ th vehicle wheel sets acting on rails, $\boldsymbol{F}\left(\boldsymbol{R}_{b}\right)$ - generalised load vector in implicit form, related to BS subsystem, $\boldsymbol{F}_{l a}\left(\boldsymbol{R}_{b}, \boldsymbol{R}_{g}\right), \boldsymbol{F}_{r a}\left(\boldsymbol{R}_{b}, \boldsymbol{R}_{g}\right)$ - generalised load vectors in implicit form, related to LAS and RAS subsystems, respectively, $\boldsymbol{F}_{l b}\left(\boldsymbol{R}_{b}, \boldsymbol{R}_{g}\right), \boldsymbol{F}_{r b}\left(\boldsymbol{R}_{b}, \boldsymbol{R}_{g}\right)$ - generalised load vectors in implicit form, related to LB and RB subsystems, respectively, $\quad \boldsymbol{F}_{r}\left(\boldsymbol{R}_{f}, \boldsymbol{R}_{w i}\right), i=$ $1,2, \ldots, N_{v}, \boldsymbol{F}_{s r}\left(\boldsymbol{R}_{s f}\right)$ - generalized load vectors in implicit form, related to OR and SR subsystems, respectively, $\quad \boldsymbol{R}_{i}=\operatorname{col}\left(R_{1 i} R_{2 i} \ldots R_{10 i}\right)$-vector of vertical interactions transmitted by 1 st and 2 nd stage suspensions of $i$ th vehicle, $\boldsymbol{G}$ - generalized load vector reflecting static pressures of wheel sets onto rails, $\boldsymbol{F}_{i}\left(\boldsymbol{R}_{i}, \boldsymbol{G}\right), i=1,2, \ldots, N_{v}$-generalised load vector in implicit form, related to $\mathrm{RV} i, i=1,2, \ldots, N_{v}$ subsystem, $\quad\left(^{\prime}\right)=d / d t$-differentiation symbol with respect to time variable $t$. Detailed formulae defining matrices and vectors in Eqs. (1) are given in Ref. [5].

Numerical research has been carried out for a German passenger train ICE-3.The enhanced Matsuura model of a rail-vehicle equipped with two two-axle bogies is applied. Wheel sets of the vehicle are modeled as point masses vibrating vertically, each with 1DOF (vertical translation). Bogie frames are modeled as rigid disks, each with $2 \mathrm{DOF}$ (vertical translation and rotation). The carbody is also modeled as a disk with 2DOF. Suspensions of the first and second stages are linear viscoelastic. The masses modeling the wheel sets are fitted with one-sided vertical springs of nonlinear Hertzian contact stiffness reflecting wheel set-rails contact. Detailed description of the rail-vehicle modeling is presented in Ref. [5].

Based on Eq. (1) and remaining formulae presented in Ref. [5], the authors developed a computer program in Delphi for simulation of dynamic processes in BTT systems.

\section{Modeling of Wheel-Rail Contact Stiffness and Random Vertical Track Irregularities}

Advanced modeling of the wheel-rail contact stiffness according to the Hertz theory is presented by Lei and Noda [2]. Wheel-rail contact is considered as two elastic contact cylinders perpendicular to each other. The relative vertical shortening between the wheel and the rail is calculated from the conventional Hertz formula:

$$
u_{H}=d_{H} R_{1}^{2 / 3}
$$

where, $u_{H}$-vertical shortening, $d_{H}=1 / k_{H}$-contact compliance, $k_{H}$-contact stiffness, $R_{1}=0.5 R$ - half of the interaction force per wheel set. Eq. (2) gives:

$$
R_{1}=\left(k_{H} u_{H}\right)^{3 / 2} \text {. }
$$

The average value of the contact stiffness coefficient (between new and worn wheel tread) is used, i.e., $k_{H}=0.216 \times 10^{8}\left(\frac{\mathrm{N}^{2 / 3}}{\mathrm{~m}}\right)$.

In reference to modeling of random track irregularity samples, only the vertical profile (elevation irregularity), i.e., the mean vertical elevation of two rails, is taken into consideration. Short wavelength corrugation irregularities in rail are neglected. According to the assumptions, design geometry 
irregularities in track formation does not exist in the BTT system. A stationary and ergodic Gaussian process in space is characterized by one-sided PSD function $S_{r r}(\Omega)$, with $\Omega=2 \pi / L_{r}(\mathrm{rad} / \mathrm{m})$ as a spatial frequency and $L_{r}$ as wavelength. The most common definition of $S_{r r}(\Omega)$ is presented by Fryba [16] and was elaborated by FRA USA (Federal Railroad Administration) in the form:

$$
S_{r r}(\Omega)=k A \frac{\Omega_{c}^{2}}{\left(\Omega^{2}+\Omega_{c}^{2}\right) \Omega^{2}}\left(\frac{\mathrm{mm}^{2} \mathrm{~m}}{\operatorname{rad}}\right)
$$

where, $k=0.25, \Omega_{c}=0.8245(\mathrm{rad} / \mathrm{m})$ Coefficient $A$ $\left(\mathrm{mm}^{2} \mathrm{rad} / \mathrm{m}\right)$ is specified for line grades 1-6. Only lines with grades $4(A=53.76), 5(A=20.95)$, and $6(A=3.39)$ are considered in the numerical research.

Random samples of track irregularity vertical profile are generated with the Monte-Carlo method which results in the following formula [16]:

$$
r(x)=2 \sum_{i=1}^{N_{r}} \sqrt{S_{r r}\left(\Omega_{\mathrm{i}}\right) \Delta \Omega} \cos \left(\Omega_{i} x+\varphi_{i}\right)(\mathrm{mm})(5)
$$

where,

$\Omega_{i}=\Omega_{\min }+(\mathrm{i}-0.5) \Delta \Omega$ - discrete frequency;

$\varphi_{i}$-random phase angle uniformly distributed over $[0,2 \pi]$ (rad) interval and independent for $i=$ $1,2, \ldots, N_{r}$

$$
\Delta \Omega=\frac{1}{\mathrm{~N}_{\mathrm{r}}}\left(\Omega_{\max }-\Omega_{\min }\right) \text {-frequency increment; }
$$

$N_{r}$ - total number of frequency increments in $\left[\Omega_{\text {min }}, \Omega_{\text {max }}\right]$ interval;

$\Omega_{\min }=\frac{2 \pi}{L_{r, \max }}, \Omega_{\max }=\frac{2 \pi}{L_{r, \min }}-$ lower and upper limits of spatial frequency;

$L_{r \text {, min }}, L_{r, \max }$ - lower and upper limits of wavelength. Taking into account the experimental data available in Refs. [2, 4, 16-18], the values $L_{r, \min }=$ $0.10 \mathrm{~m}, L_{r, \max }=70.00 \mathrm{~m}$ are assumed as adequate to simulate vibrations of single span bridges of span length to $30.00 \mathrm{~m}$. Based on the preliminary simulations, value of $N_{r}=100$ was assessed to be the most adequate to obtain correct output samples close to reality [6].

\section{Design Conditions for Bridges Located on High-Speed Railways}

Railway bridges loaded by high-speed trains need to be designed or modernized to ensure the TSC and the PCC among the others [19, 20]. Excessive bridge deformations can endanger railway traffic by creating unacceptable changes in vertical and horizontal track geometry and excessive stresses in rails. Excessive vibrations can lead to ballast instability and unacceptable reduction in wheel-rail contact forces.

The TSC condition is expressed by the limit vertical acceleration of a bridge deck [20], $a_{\mathrm{p}, \mathrm{lim}}=3.50 \mathrm{~m} / \mathrm{s}^{2}$. The PCC condition can be related to a carbody vertical acceleration. The indicative levels of comfort, expressed by the vertical acceleration $a_{\mathrm{b}, \mathrm{lim}}$ inside the carriage during the travel, are specified in Table 3 [19].

The SC is expressed by the limit vertical deflection of the bridge span under a real train [19], $w_{\text {lim }}=$ $L / 1,700$. In order to assess fatigue durability of the bridge superstructure, the DC related to longitudinal normal stresses in the bottom fibers of the main steel beams at the midspan is applied in the form [4]:

$$
\begin{aligned}
& \sigma_{f}(0.5 L)=\sigma_{g k}(0.5 L)+\sigma_{m}(0.5 L)+\zeta \sigma_{a}(0.5 L) \leq \\
& \sigma_{\lim }
\end{aligned}
$$

where,

$\sigma_{f}(0.5 L)$-equivalent normal stress including high-cycle fatigue;

$\sigma_{g k}(0.5 L)$-normal stress due to characteristic weight of bridge;

$\sigma_{m}(0.5 L)$ - average normal stress corresponding to extreme quasi-steady-state vibrations;

$\sigma_{a}(0.5 L)$ - amplitude of normal stress corresponding to extreme quasi-steady-state vibrations;

$\zeta$ - high-cycle fatigue factor;

$\sigma_{\text {lim }}$-admissible normal stress.

Table 3 The indicative levels of passenger comfort.

\begin{tabular}{ll}
\hline Level of comfort & $a_{b, \lim }\left(\mathrm{m} / \mathrm{s}^{2}\right)$ \\
\hline Very good & 1.0 \\
Good & 1.3 \\
Acceptable & 2.0 \\
\hline
\end{tabular}


Eq. (6) is obtained from the Schmidt graph approximated with an open polygon, assuming a constant safety factor. If Eq. (6) is satisfied, full durability of the bridge with a safety margin is protected. For S235W structural steel, the high-cycle fatigue factor is $\zeta=2.35$ and the admissible normal stress equals $\sigma_{\text {lim }}=f_{y k} / n_{s}$ where, $f_{y k}=235$ $\mathrm{MPa}$-yield strength, $n_{s}$ - safety margin (safety coefficient).

\section{Prediction of Forced Resonances}

The BTT system is nonlinear physically in reference of ballast and rail fastenings and maps geometrically infinite track approximately via finitely long out-of-approach zones of the track. Based on preliminary simulations, it is concluded that the BT (bridge/track structure) subsystem exhibits modal characteristics similar to those for a linear system. Fundamental modal characteristic of the BT subsystem, called in this study the fundamental quasi natural frequency of quasi free damped vibrations, can be identified when the moving train is in the right out-of-approach zone of the track. Simulations for identifying the fundamental quasi natural frequency of the physically nonlinear BT subsystem were performed for operating speed $v=250 \mathrm{~km} / \mathrm{h}$. Approximate values of the fundamental quasi natural period and frequency are calculated from formulae:

$$
T_{1}=\frac{s}{v}, f_{1}=\frac{1}{T_{1}}
$$

where, $s$ - distance of the load head over one cycle of quasi free damped vibrations. Periods of subsequent harmonic components of the static excitation of the BT subsystem are:

$$
\bar{T}_{i}=\frac{l}{i v}, i=1,2, \ldots
$$

where, $l=24.78 \mathrm{~m}$-total length of a repeatable rail-vehicle in an ICE-3 train. Prediction of the resonant operating speeds, corresponding to equality of the fundamental quasi natural period and subsequent harmonic components of the static excitation, is as follows:

$$
T_{1}=\bar{T}_{i} \Rightarrow v_{i 1}=\frac{l}{i T_{1}}(i=1,2, \ldots)
$$

Due to parametric effects resulting from quasi unsprung moving masses (wheel sets), the more exact resonant operating speeds are lower by about $1.5 \%$ compared to the values calculated from Eq. (9). This phenomenon was detected based on preliminary simulations of dynamic processes in BTT systems. Predicted resonant operating speeds decreased by about $1.5 \%$ are summarized in Table 4 .

\section{Output Quantities and Numerical Analysis of BTT Systems}

The following output quantities are defined (Fig. 3):

- $w(0.5 L, t)$-deflection of bridge superstructure at midspan (mm);

- $\sigma(0.5 L, t)$-longitudinal normal stress in bottom fibres of main beams, at midspan (MPa);

- $a_{\mathrm{p}}(0.5 L, t)$ - vertical acceleration of RC platform, at midspan $\left(\mathrm{m} / \mathrm{s}^{2}\right)$;

- $R_{k i}(t), k=1,2,3,4, i=1,2, \ldots, N_{v}$-dynamic pressure forces of wheel sets onto rails $(\mathrm{kN})$;

- $a_{b i \alpha}(t), i=1,2, \ldots, N_{v}, \alpha=f, r$-vertical accelerations of carbodies at pivots over front and rear bogies $\left(\mathrm{m} / \mathrm{s}^{2}\right)$.

The following design quantities are defined:

$$
\begin{gathered}
w_{\max }=\max _{t} w(0.5 L, t)(\mathrm{mm}) \\
\sigma_{\max }=\max _{t} \sigma(0.5 L, t)(\mathrm{MPa}) \\
a_{\mathrm{p}, \max }=\max _{t}\left|a_{p}(0.5 L, t)\right|\left(\mathrm{m} / \mathrm{s}^{2}\right) \\
R_{\min }=\min _{t}\left\{R_{k i}(t)\right\}(\mathrm{kN}) \\
a_{\mathrm{b}, \max }=\max _{t}\left\{\left|a_{b i \alpha}(t)\right|\right\}\left(\mathrm{m} / \mathrm{s}^{2}\right)
\end{gathered}
$$

Impact factors in deflection and longitudinal normal stress in bottom fibres of the main beams at the midspan are calculated from well-known classic formulae, i.e.

Table 4 Predicted resonant operating speeds.

\begin{tabular}{lcccccr}
\hline \multirow{2}{*}{ Bridge code } & $f_{1}(\mathrm{~Hz})$ & \multicolumn{5}{c}{ Resonant operating speed $(\mathrm{km} / \mathrm{h})$} \\
\cline { 3 - 7 } & & $\boldsymbol{v}_{\mathbf{1 1}}$ & $\boldsymbol{v}_{\mathbf{2 1}}$ & $\boldsymbol{v}_{\mathbf{3 1}}$ & $\boldsymbol{v}_{\mathbf{4 1}}$ & $\boldsymbol{v}_{\mathbf{5 1}}$ \\
\hline SCB-15 & 6.14 & 540 & 270 & 180 & 135 & 108 \\
SCB-18 & 5.14 & 450 & 225 & 149 & 112 & 90 \\
SCB-21 & 4.62 & 407 & 203 & 135 & 101 & 82 \\
SCB-24 & 4.20 & 370 & 185 & 123 & 93 & 74 \\
SCB-27 & 3.90 & 343 & 171 & 114 & 86 & 69 \\
\hline
\end{tabular}




$$
\begin{gathered}
\varphi_{w}(0.5 L)=\frac{\max _{t} w(0.5 L, t)}{\max _{t} w_{s}(0.5 L, t)} \\
\varphi_{\sigma}(0.5 L)=\frac{\max _{t} \sigma(0.5 L, t)}{\max _{t} \sigma_{s}(0.5 L, t)}
\end{gathered}
$$

where,

$$
w(0.5 L, t), \sigma(0.5 L, t) \text {-dynamic vertical deflection }
$$
and dynamic longitudinal normal stress, simulated without or with random track irregularities, for selected resonant and extra resonant operating speeds;

$$
w_{s}(0.5 L, t), \sigma_{s}(0.5 L, t) \quad \text {-quasi-static vertical }
$$
deflection and quasi-static longitudinal normal stress, simulated for $v=30 \mathrm{~km} / \mathrm{h}$ and for a smooth track.

Vertical track irregularities are a random factor in the physically nonlinear BTT system. Random samples of these irregularities are calculated using the Monte-Carlo method according to Eq. (5). Six design quantities were defined in previous considerations, i.e., $\varphi_{w}(0.5 L), \varphi_{\sigma}(0.5 L), \sigma_{f}(0.5 L), a_{p, \max }, a_{b, \max }, R_{\min }$, and they can be treated as random continuous variables. Let $Z$ be a selected random continuous variable. There is considered an $n$-element simple random sample $\left(Z_{1}, Z_{2}, \ldots, Z_{n}\right)$. Basic statistics (expectance $E(Z)$ standard deviation $D(Z)$ ) of the $n$-element sample and their estimators are calculated using well-known classic formulae [15].

Numerical research has been performed for all bridges forming the BTT series-of-types, using values of parameters of the subsystems set up in Ref. [15]. A time step $h=2 \times 10^{-5} \mathrm{~s}$ was assumed in numerical integration of equations of motions using the Newmark average acceleration scheme and linear prediction of the interactions. This value protects good accuracy of the output quantities both qualitatively and quantitatively. The extreme values of the output quantities were searched in each time step while time histories were registered with a bigger output time step corresponding to 2,000 output points. The parameter $\varepsilon$ in the iteration ending condition put on the interaction forces was assumed to be equal to $\varepsilon=10^{-8} \mathrm{~N}$. The allowed number of iterations equaled 15 .

The simulations were conducted for the ICE-3 train moving at the most dangerous resonant operating velocities and at the maximum operating velocity $v_{\max }=300 \mathrm{~km} / \mathrm{h}$.

Values of the design quantities for a smooth track (without track irregularities) are given in Table 5 . Based on Table 5, the following conclusions are formulated:

(1) Values of the impact factor in deflection for subsequent bridges, corresponding to an ICE-3 Train moving on a smooth track, differ from each other. At resonant operating velocities, this factor takes the maximum value 3.06 for the shortest bridge SCB-15. At the maximum operating speed, this factor takes the maximum value 2.11 for the longest bridge SCB-27. Some resonant velocities for SCB-18 and SCB-21 bridges do not induce resonance amplification effect. The SC condition $w_{\max } \leq w_{\text {lim }}=L / 1,700$ is satisfied for all objects forming the SCB series-of-types, loaded by an ICE-3 high-speed train moving at operating speeds to $300 \mathrm{~km} / \mathrm{h}$;

(2) Values of the impact factor in stress for subsequent bridges, corresponding to an ICE-3 train

\begin{tabular}{|c|c|c|c|c|c|c|}
\hline Code & $\begin{array}{l}v \\
(\mathrm{~km} / \mathrm{h})\end{array}$ & $\begin{array}{l}w_{\max } \\
(\mathrm{mm})\end{array}$ & $\begin{array}{l}\sigma_{\max } \\
(\mathrm{MPa})\end{array}$ & $\begin{array}{l}a_{p, \max } \\
\left(\mathrm{m} / \mathrm{s}^{2}\right)\end{array}$ & $\begin{array}{l}R_{\min } \\
(\mathrm{kN})\end{array}$ & $\begin{array}{l}a_{b, \max } \\
\left(\mathrm{m} / \mathrm{s}^{2}\right)\end{array}$ \\
\hline \multirow{4}{*}{ SCB-15 } & 30 & 2.20 & 13.00 & 0.02 & 156.4 & 0.03 \\
\hline & 270 & 5.82 & 38.25 & 6.12 & 136.5 & 0.22 \\
\hline & 180 & 6.74 & 43.29 & 7.44 & 141.4 & 0.24 \\
\hline & 300 & 4.37 & 27.18 & 3.75 & 138.7 & 0.12 \\
\hline \multirow{4}{*}{ SCB-18 } & 30 & 2.88 & 14.13 & 0.01 & 156.3 & 0.03 \\
\hline & 225 & 2.89 & 15.24 & 0.92 & 145.7 & 0.13 \\
\hline & 149 & 5.80 & 29.42 & 2.99 & 150.6 & 0.19 \\
\hline & 300 & 5.28 & 26.61 & 2.60 & 140.6 & 0.18 \\
\hline \multirow{4}{*}{ SCB-21 } & 30 & 3.22 & 14.01 & 0.01 & 156.3 & 0.02 \\
\hline & 203 & 5.38 & 24.32 & 1.94 & 150.4 & 0.21 \\
\hline & 135 & 3.79 & 17.17 & 0.78 & 154.6 & 0.11 \\
\hline & 300 & 5.87 & 26.00 & 2.59 & 141.4 & 0.19 \\
\hline \multirow{4}{*}{ SCB-24 } & 30 & 3.51 & 13.67 & 0.01 & 156.3 & 0.02 \\
\hline & 185 & 6.41 & 25.61 & 2.10 & 151.9 & 0.27 \\
\hline & 123 & 6.47 & 25.92 & 2.20 & 149.9 & 0.30 \\
\hline & 300 & 7.09 & 27.88 & 2.62 & 143.7 & 0.28 \\
\hline \multirow{4}{*}{ SCB-27 } & 30 & 3.66 & 13.31 & 0.02 & 156.4 & 0.02 \\
\hline & 171 & 5.65 & 20.78 & 1.25 & 153.2 & 0.25 \\
\hline & 114 & 5.13 & 19.05 & 1.02 & 153.0 & 0.22 \\
\hline & 300 & 7.74 & 28.16 & 2.65 & 145.5 & 0.30 \\
\hline
\end{tabular}
moving on a smooth track, also differ from each other.

Table 5 Values of design quantities for bridges forming SCB series-of-types related to ICE-3 train and smooth track. 
At resonant operating velocities, this factor takes the maximum value 3.33 for the shortest bridge SCB-15. At the maximum operating speed, this factor takes the maximum value 2.12 for the longest bridge SCB-27. Some resonant velocities for SCB-18 and SCB-21 bridges do not induce resonance amplification effect. The DC condition is satisfied with safety margin about 1.50 for all objects forming the SCB series-of-types, loaded by an ICE-3 high-speed train moving at operating speeds to $300 \mathrm{~km} / \mathrm{h}$;

(3) The TSC condition $a_{p, \max } \leq a_{p, \lim }=3.50 \mathrm{~m} / \mathrm{s}^{2}$ is satisfied for bridges SCB-18, SCB-21, SCB-24, SCB-27. For bridge SCB-15, this condition is exceeded about two times at resonant operating speeds and weakly satisfied for the maximum operating speed;

(4) The extreme drop in dynamic pressures of ICE-3 train wheel sets is observed for SCB-15 bridge at the resonant operating speed $v_{21}=270 \mathrm{~km} / \mathrm{h}$ and is equal to $87 \%$ of the static pressure force. This drop does not exceed the limit value $75 \%$ [4]. Reduction in wheel/rail contact forces is acceptable for all objects forming the SCB series-of-types, loaded by an ICE-3 high-speed train moving at operating speeds $\leq 300 \mathrm{~km} / \mathrm{h}$;

(5) The PCC condition $a_{b, \max } \leq a_{b \text {,lim }}$ is satisfied on a very good level for all objects forming the SCB series-of-types, loaded by an ICE-3 train moving at operating speeds $\leq 300 \mathrm{~km} / \mathrm{h}$.

The following codes are introduced: QSR — quasi-static response, DR - dynamic response, $\mathrm{RS}$-random simulation example, NTI-no track irregularities, TI4, TI5, TI6-random track irregularities at Line Grades 4, 5 and 6, respectively. Numerical studies on the impact of random track irregularities were carried out for all objects forming the SCB series-of-types. In the paper, these studies are presented in detail for the SCB-15 bridge. The values of selected design quantities, corresponding to passages of an ICE-3 train at service velocities $v=30$ $\mathrm{km} / \mathrm{h}$ (quasi-static passage), $v_{31}=180 \mathrm{~km} / \mathrm{h}, v_{21}=$ $270 \mathrm{~km} / \mathrm{h}$ (resonant velocities), $v_{\max }=300 \mathrm{~km} / \mathrm{h}$, are summarized in Table 6. Passages on the smooth track
(NTI) are deterministic. Passages on the track with vertical irregularities TI6, TI5, TI4 correspond to a single RS (random sample). Time-histories of selected output quantities, corresponding to the resonant speed $v_{21}=270 \mathrm{~km} / \mathrm{h}$, are shown in Figs. 5-9.

Basic statistics of the design quantities for the system $\mathrm{BTT}=\mathrm{SCB}-15 / \mathrm{BT} / \mathrm{ICE}-3$ with track irregularities TI4 and TI5, at speeds $v_{31}=180 \mathrm{~km} / \mathrm{h}$, $v_{21}=270 \mathrm{~km} / \mathrm{h}$, and $v_{\max }=300 \mathrm{~km} / \mathrm{h}$, are summarized in Tables 7-12. The statistics are calculated for 20-element random samples. The interval $\left[Z_{l}, Z_{u}\right]$ contains the values of a random variable $Z$ with 20 samples.

Tables 13-15 show values of impact factors $\varphi_{w}(0.5 L), \varphi_{\sigma}(0.5 L)$, calculated for $Z_{u}$, and testing the durability condition in cases of a smooth track, track irregularities TI5, and track irregularities TI4. Estimation from the top is adopted in the form of:

$$
\begin{gathered}
\sigma_{m}(0.5 L)=\beta \max _{t} \sigma_{s}(0.5 L, t)=0.65 \mathrm{MPa} \\
\sigma_{a}(0.5 \mathrm{~L})=\sigma_{\max }-\sigma_{m}(0.5 L)
\end{gathered}
$$

Table 6 Values of design quantities for BTT =

\begin{tabular}{|c|c|c|c|c|c|}
\hline $\begin{array}{l}v \\
(\mathrm{~km} / \mathrm{h})\end{array}$ & TI & $\begin{array}{l}W_{\max } \\
(\mathrm{mm})\end{array}$ & $\begin{array}{l}\sigma_{\max } \\
(\mathrm{MPa})\end{array}$ & $\begin{array}{l}a_{p, \max } \\
a_{b, \max } \\
\left(\mathrm{m} / \mathrm{s}^{2}\right)\end{array}$ & $\begin{array}{l}R_{\min } \\
(\mathrm{kN})\end{array}$ \\
\hline 30 & NTI & 2.20 & 13.00 & $\begin{array}{l}0.02 \\
0.03\end{array}$ & 156.4 \\
\hline 180 & NTI & 6.74 & 43.29 & $\begin{array}{l}7.44 \\
0.24\end{array}$ & 141.4 \\
\hline 180 & TI6 RS & 6.92 & 44.78 & $\begin{array}{l}9.56 \\
0.42\end{array}$ & 49.9 \\
\hline 180 & TI5 RS & 6.39 & 42.06 & $\begin{array}{r}12.92 \\
0.66\end{array}$ & 0.0 \\
\hline 180 & TI4 RS & 5.76 & 42.42 & $\begin{array}{r}16.29 \\
1.08\end{array}$ & 0.0 \\
\hline 270 & NTI & 5.82 & 38.25 & $\begin{array}{l}6.12 \\
0.22\end{array}$ & 136.5 \\
\hline 270 & TI6 RS & 5.99 & 40.01 & $\begin{array}{r}10.25 \\
0.40\end{array}$ & 21.2 \\
\hline 270 & TI5 RS & 6.57 & 44.39 & $\begin{array}{r}18.03 \\
0.63\end{array}$ & 0.0 \\
\hline 270 & TI4 RS & 4.95 & 43.62 & $\begin{array}{r}57.88 \\
1.10\end{array}$ & 0.0 \\
\hline 300 & NTI & 4.37 & 27.18 & $\begin{array}{l}3.75 \\
0.12\end{array}$ & 138.7 \\
\hline 300 & TI6 RS & 4.28 & 27.51 & $\begin{array}{l}6.47 \\
0.23\end{array}$ & 0.0 \\
\hline 300 & TI5 RS & 4.29 & 29.26 & $\begin{array}{r}12.71 \\
0.41\end{array}$ & 0.0 \\
\hline 300 & TI4 RS & 4.19 & 33.84 & $\begin{array}{r}34.85 \\
0.74 \\
\end{array}$ & 0.0 \\
\hline
\end{tabular}
SCB-15/BT/ICE-3 system. 


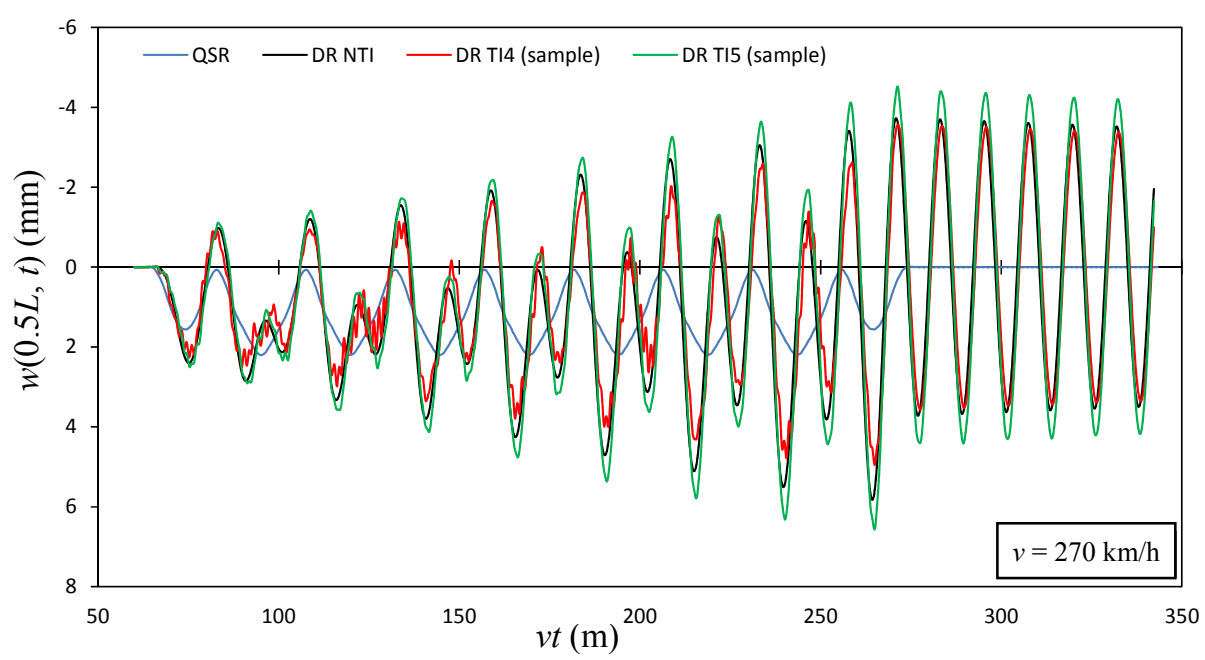

Fig. 5 System BTT $=$ SCB-15/BT/ICE-3. Deflection $w(0.5 L, t)(\mathrm{mm})$ corresponding to $v_{21}=270 \mathrm{~km} / \mathrm{h}$.

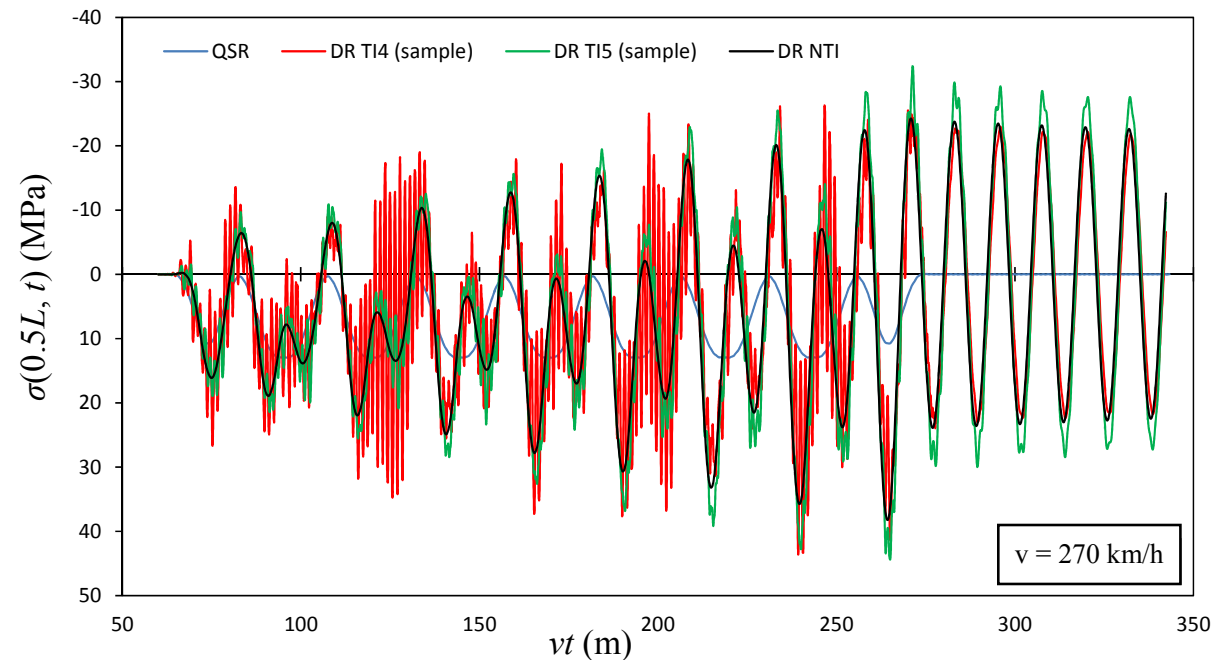

Fig. 6 System BTT $=$ SCB-15/BT/ICE-3. Stress $\sigma(0.5 L, t)(\mathrm{MPa})$ corresponding to $v_{21}=270 \mathrm{~km} / \mathrm{h}$.

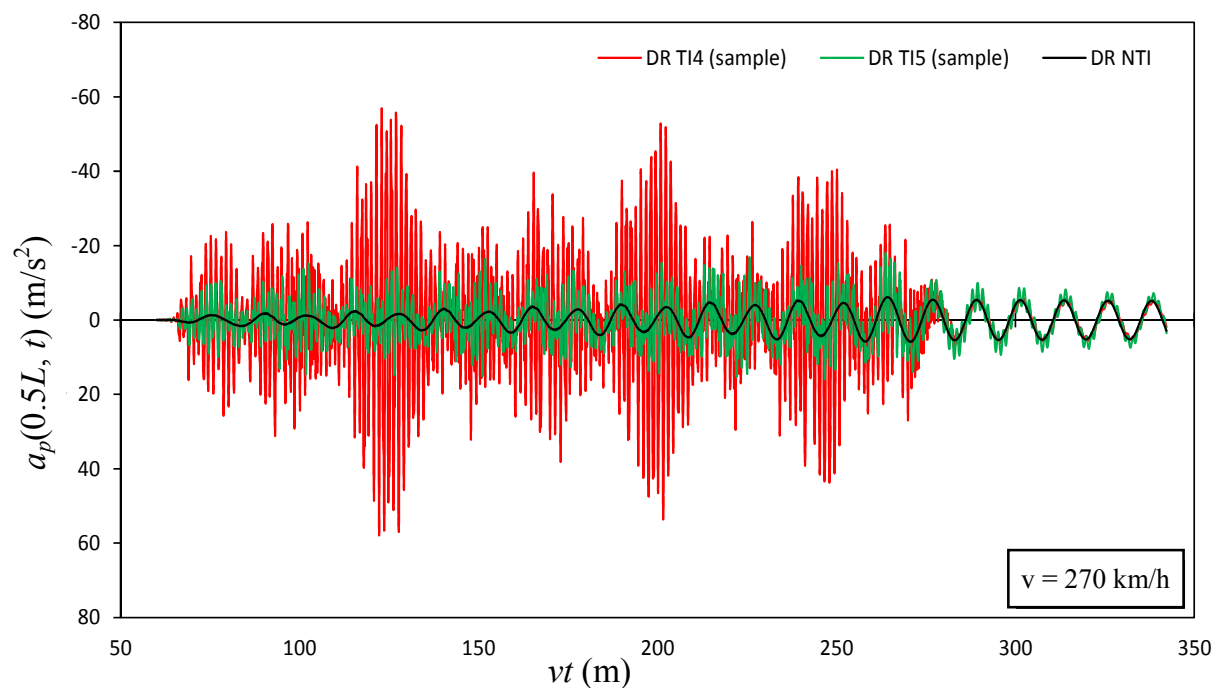

Fig. 7 System BTT $=$ SCB-15/BT/ICE-3. Acceleration $a_{p}(0.5 L, t)\left(\mathrm{m} / \mathrm{s}^{2}\right)$ corresponding to $v_{21}=270 \mathrm{~km} / \mathrm{h}$. 


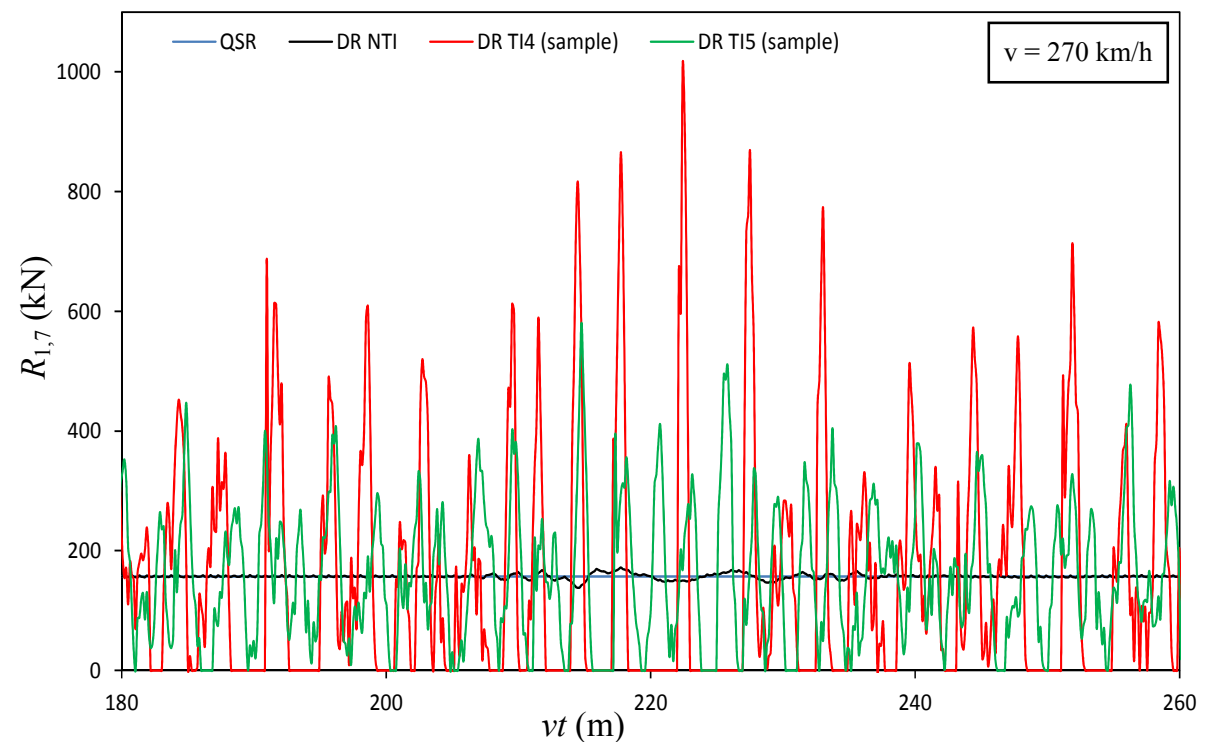

Fig. 8 System BTT $=$ SCB-15/BT/ICE-3. Pressure $R_{1,7}(t)(\mathrm{kN})$ corresponding to $v_{21}=270 \mathrm{~km} / \mathrm{h}$.

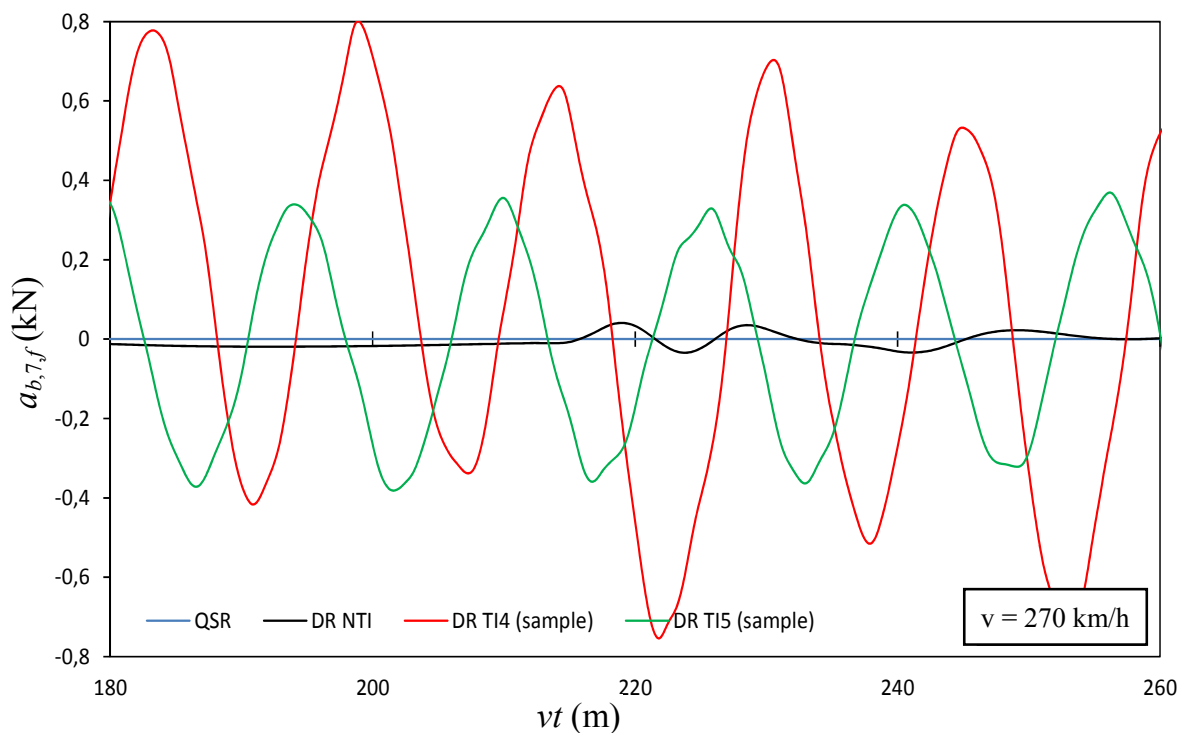

Fig. 9 System BTT $=$ SCB-15/BT/ICE-3. Acceleration $a_{b, 7, f}(t)\left(\mathrm{m} / \mathrm{s}^{2}\right)$ corresponding to $v_{21}=270 \mathrm{~km} / \mathrm{h}$.

Table 7 System BTT $=$ SCB-15/BT/ICE-3 with track irregularities TI4. Basic statistics of design quantities for resonant speed $v_{31}=180 \mathrm{~km} / \mathrm{h}$.

\begin{tabular}{llrlcl}
\hline Quantity & TI & $\begin{array}{r}w_{\max } \\
(\mathrm{mm})\end{array}$ & $\begin{array}{l}\sigma_{\max } \\
(\mathrm{MPa})\end{array}$ & $\begin{array}{c}a_{p, \max } \\
\left(\mathrm{m} / \mathrm{s}^{2}\right)\end{array}$ & $\begin{array}{l}a_{b, \max } \\
\left(\mathrm{m} / \mathrm{s}^{2}\right)\end{array}$ \\
\hline$Z$ & NTI & 6.74 & 43.29 & 7.44 & 0.24 \\
$Z_{l}$ & TI4 & 3.02 & 22.37 & 11.62 & 0.86 \\
$Z_{u}$ & TI4 & 10.79 & 72.95 & 27.25 & 1.14 \\
$E(Z)$ & TI4 & 6.94 & 47.84 & 19.61 & 0.98 \\
$\mathrm{D}(Z)$ & TI4 & 2.12 & 13.97 & 3.95 & 0.07 \\
\hline
\end{tabular}

Table 8 System BTT $=$ SCB-15/BT/ICE-3 with track irregularities TI4. Basic statistics of design quantities for resonant speed $v_{21}=270 \mathrm{~km} / \mathrm{h}$.

\begin{tabular}{llllrl}
\hline Quantity & TI & $\begin{array}{l}w_{\max } \\
(\mathrm{mm})\end{array}$ & $\begin{array}{l}\sigma_{\max } \\
(\mathrm{MPa})\end{array}$ & $\begin{array}{c}a_{p, \max } \\
\left(\mathrm{m} / \mathrm{s}^{2}\right)\end{array}$ & $\begin{array}{l}a_{b, \max } \\
\left(\mathrm{m} / \mathrm{s}^{2}\right)\end{array}$ \\
\hline$Z$ & NTI & 5.82 & 38.25 & 6.12 & 0.22 \\
$Z_{l}$ & TI4 & 4.19 & 29.21 & 23.58 & 0.76 \\
$Z_{u}$ & TI4 & 8.18 & 56.66 & 40.16 & 1.07 \\
$E(Z)$ & TI4 & 6.13 & 44.49 & 31.88 & 0.94 \\
$D(Z)$ & TI4 & 1.14 & 7.92 & 5.16 & 0.07 \\
\hline
\end{tabular}


Table 9 System BTT $=$ SCB-15/BT/ICE-3 with track irregularities TI4. Basic statistics of design quantities for maximum speed $v_{\max }=300 \mathrm{~km} / \mathrm{h}$.

\begin{tabular}{llllrl}
\hline Quantity & TI & $\begin{array}{l}w_{\max } \\
(\mathrm{mm})\end{array}$ & $\begin{array}{l}\sigma_{\max } \\
(\mathrm{MPa})\end{array}$ & $\begin{array}{r}a_{p, \max } \\
\left(\mathrm{m} / \mathrm{s}^{2}\right)\end{array}$ & $\begin{array}{l}a_{b, \max } \\
\left(\mathrm{m} / \mathrm{s}^{2}\right)\end{array}$ \\
\hline$Z$ & NTI & 4.37 & 27.18 & 3.75 & 0.12 \\
$Z_{l}$ & TI4 & 3.81 & 31.86 & 19.83 & 0.65 \\
$Z_{u}$ & TI4 & 5.45 & 44.55 & 43.02 & 0.92 \\
$E(Z)$ & TI4 & 4.79 & 38.24 & 32.98 & 0.78 \\
$D(Z)$ & TI4 & 0.51 & 3.34 & 5.61 & 0.07 \\
\hline
\end{tabular}

Table 10 System BTT $=$ SCB-15/BT/ICE-3 with track irregularities TI5. Basic statistics of design quantities for resonant speed $v_{31}=180 \mathrm{~km} / \mathrm{h}$.

\begin{tabular}{llllrl}
\hline Quantity & TI & $\begin{array}{r}w_{\max } \\
(\mathrm{mm})\end{array}$ & $\begin{array}{l}\sigma_{\max } \\
(\mathrm{MPa})\end{array}$ & $\begin{array}{r}a_{p, \max } \\
\left(\mathrm{m} / \mathrm{s}^{2}\right)\end{array}$ & $\begin{array}{l}a_{b, \max } \\
\left(\mathrm{m} / \mathrm{s}^{2}\right)\end{array}$ \\
\hline$Z$ & NTI & 6.74 & 43.29 & 7.44 & 0.24 \\
$Z_{l}$ & TI5 & 5.04 & 34.29 & 9.20 & 0.52 \\
$Z_{u}$ & TI5 & 9.27 & 59.54 & 17.32 & 0.82 \\
$E(Z)$ & TI5 & 7.20 & 47.59 & 12.80 & 0.67 \\
$D(Z)$ & TI5 & 1.17 & 7.28 & 2.30 & 0.07 \\
\hline
\end{tabular}

Table 11 System BTT $=$ SCB-15/BT/ICE-3 with track irregularities TI5. Basic statistics of design quantities for resonant speed $v_{21}=270 \mathrm{~km} / \mathrm{h}$.

\begin{tabular}{lllrrl}
\hline Quantity & TI & $\begin{array}{r}w_{\max } \\
(\mathrm{mm})\end{array}$ & $\begin{array}{l}\sigma_{\max } \\
(\mathrm{MPa})\end{array}$ & $\begin{array}{r}a_{p, \max } \\
\left(\mathrm{m} / \mathrm{s}^{2}\right)\end{array}$ & $\begin{array}{l}a_{b, \max } \\
\left(\mathrm{m} / \mathrm{s}^{2}\right)\end{array}$ \\
\hline$Z$ & NTI & 5.82 & 38.25 & 6.12 & 0.22 \\
$Z_{l}$ & TI5 & 4.37 & 31.17 & 14.31 & 0.48 \\
$Z_{u}$ & TI5 & 7.06 & 47.80 & 24.28 & 0.69 \\
$E(Z)$ & TI5 & 5.77 & 40.74 & 18.91 & 0.59 \\
$D(Z)$ & TI5 & 0.78 & 5.08 & 2.31 & 0.06 \\
\hline
\end{tabular}

Table 12 System BTT $=$ SCB-15/BT/ICE-3 with track irregularities TI5. Basic statistics of design quantities for maximum speed $v_{\max }=300 \mathrm{~km} / \mathrm{h}$.

\begin{tabular}{llllrl}
\hline Quantity & TI & $\begin{array}{l}w_{\max } \\
(\mathrm{mm})\end{array}$ & $\begin{array}{l}\sigma_{\max } \\
(\mathrm{MPa})\end{array}$ & $\begin{array}{l}a_{p, \max } \\
\left(\mathrm{m} / \mathrm{s}^{2}\right)\end{array}$ & $\begin{array}{l}a_{b, \max } \\
\left(\mathrm{m} / \mathrm{s}^{2}\right)\end{array}$ \\
\hline$Z$ & NTI & 4.37 & 27.18 & 3.75 & 0.12 \\
$Z_{l}$ & TI5 & 3.90 & 28.71 & 12.62 & 0.38 \\
$Z_{u}$ & TI5 & 4.87 & 37.36 & 28.87 & 0.55 \\
$E(Z)$ & TI5 & 4.41 & 32.82 & 19.59 & 0.45 \\
$D(Z)$ & TI5 & 0.30 & 2.53 & 4.20 & 0.05 \\
\hline
\end{tabular}

Table 13 Values of impact factors and check durability condition in system BTT $=$ SCB-15/BT/ICE-3 with smooth track (NTI).

\begin{tabular}{lllll}
\hline $\begin{array}{l}v \\
(\mathrm{~km} / \mathrm{h})\end{array}$ & $\varphi_{w}(0.5 L)$ & $\varphi_{\sigma}(0.5 L)$ & $\begin{array}{l}\sigma_{a}(0.5 L) \\
(\mathrm{MPa})\end{array}$ & $\begin{array}{l}\sigma_{f}(0.5 L) \\
(\mathrm{MPa})\end{array}$ \\
\hline 180 & 3.06 & 3.33 & 36.79 & 126.43 \\
270 & 2.65 & 2.94 & 31.75 & 114.58 \\
300 & 1.99 & 2.09 & 20.68 & 88.57 \\
\hline
\end{tabular}

Table 14 Values of impact factors and check durability condition in system BTT $=$ SCB-15/BT/ICE-3 with track irregularities TI5.

\begin{tabular}{lllll}
\hline $\begin{array}{l}v \\
(\mathrm{~km} / \mathrm{h})\end{array}$ & $\varphi_{w}(0.5 L)$ & $\varphi_{\sigma}(0.5 L)$ & $\begin{array}{l}\sigma_{a}(0.5 L) \\
(\mathrm{MPa})\end{array}$ & $\begin{array}{l}\sigma_{f}(0.5 L) \\
(\mathrm{MPa})\end{array}$ \\
\hline 180 & 4.21 & 4.58 & 53.04 & 164.61 \\
270 & 3.21 & 3.68 & 41.30 & 137.03 \\
300 & 2.21 & 2.87 & 30.86 & 112.49 \\
\hline
\end{tabular}

Table 15 Values of impact factors and check durability condition in system BTT $=$ SCB-15/BT/ICE-3 with track irregularities TI4.

\begin{tabular}{lllll}
\hline $\begin{array}{l}v \\
(\mathrm{~km} / \mathrm{h})\end{array}$ & $\varphi_{w}(0.5 L)$ & $\varphi_{\sigma}(0.5 L)$ & $\begin{array}{l}\sigma_{a}(0.5 L) \\
(\mathrm{MPa})\end{array}$ & $\begin{array}{l}\sigma_{f}(0.5 L) \\
(\mathrm{MPa})\end{array}$ \\
\hline 180 & 4.90 & 5.61 & 66.45 & 196.13 \\
270 & 3.72 & 4.36 & 50.16 & 157.85 \\
300 & 2.48 & 3.43 & 38.05 & 129.39 \\
\hline
\end{tabular}

where, $\beta=0.50, \sigma_{\max }=Z_{u}$. For subsequent bridges belonging to the SCB series-of-types, coefficient $\beta$ is properly increased. Moreover, $\sigma_{g k}(0.5 L)$ equals 33.47 MPa for the SCB-15 bridge [13].

Based on the dynamic analysis of objects forming the SCB series of railway bridges, the following main conclusions are formulated:

(1) In reference to shorter objects (SCB-15, SCB-18) in the resonant states and longer objects (SCB-24, SCB-27) at the maximum operating velocity, impact factors in deflections and stresses can greatly exceed the values specified by standards. Track irregularities can increase substantially these factors;

(2) Dynamic pressures of the moving wheel sets onto the rails are close to the quasi-static pressures in the case of a smooth track (NTI). In the case of irregularity grade TI6, a significant decrease in the value of these forces is observed in the resonance states. In the case of track irregularity grades TI5 and TI4, micro detachments of the moving wheel sets from the rails exist, resulting in very large overloads of wheel rims, caused by impacts of wheel sets onto rails. This phenomenon concerns resonant or very high operating speeds;

(3) At resonant operating speeds, random vertical track irregularities may cause detuning or increasing resonant effects in BTT systems. It depends on random 
shape of track roughness. Time histories of longitudinal normal stresses in the steel beams are affected by high frequency oscillations compared to a smooth track case;

(4) Random vertical track irregularities cause high frequency oscillations with large amplitudes in vertical accelerations of the platform. The TSC condition is mostly unsatisfied, but the crossing level decreases as a span length and a track irregularity grade increase. In the case of a smooth track, the TSC condition is not satisfied just for the SCB-15 bridge;

(5) The PCC condition is satisfied at a very good level in cases of NTI, TI6 and TI5 irregularity grades, and at a good level in the case of TI4 irregularity grade for all objects forming the SCB series-of-types and for all operating speeds to $300 \mathrm{~km} / \mathrm{h}$;

(6) The SC condition as related to bridge deflections is satisfied for all objects forming the SCB series-of-types, for irregularity grade TI4 and higher, for operating speeds to $300 \mathrm{~km} / \mathrm{h}$;

(7) The DC condition is satisfied for all objects forming the SCB series-of-types and NTI, TI6, TI5, TI4 track irregularity grades, but with different values of the safety margin. For example, for the SCB-15 bridge with TI4 irregularities, the safety margin is $n_{s} \geq 1.20$, whereas for the SCB-27 bridge with TI5 irregularities, this margin takes values $n_{s} \geq 1.62$;

(8) Expectances of the design quantities $w_{\max }, \sigma_{\max }$ for systems with TI4, TI5 track irregularities are higher than the values of these quantities for systems with a smooth track (NTI);

(9) Objects forming the SCB series-of-types meet all design conditions (SC, DC, TSC and PCC) and can be used for high-speed railways, provided that:

- Random vertical track irregularity grade is the highest (TI6);

- A thicker layer of macadam ballast (about $50 \mathrm{~cm}$ ) under a sleeper is applied on the bridge and in the approach zones (in order to satisfy the TSC condition);

- Operating speeds are $\leq 270 \mathrm{~km} / \mathrm{h}$;

- In reference to SCB-15 and SCB-18 bridges, trains move at extra resonant operation speeds (velocities close to $v_{31}, v_{21}$ are excluded).

\section{General Conclusions}

Based on numerical dynamic analysis of virtual models of SCB composite bridge/ballasted track structure/high-speed ICE-3 train systems, the following general conclusions are formulated:

(1) Number of random vertical irregularities of 20 is sufficient to determine the basic statistics $\mathrm{E}(Z)$ and $D(Z)$ of the design quantities in BTT systems;

(2) Graphs of the design quantities with respect to an operating speed contain resonance peaks which decrease as a bridge span increases;

(3) Impact factors in deflections and stresses greatly exceed the values specified by standards. Track irregularities can increase these factors substantially;

(4) Dynamic pressures of the moving wheel sets onto the rails are close to the quasi static pressures in the case of a smooth track (NTI). In the case of irregularity grade TI6, a significant decrease in the value of these forces is observed in the resonance states. In the case of track irregularity grades TI5 and TI4, micro detachments of the moving wheel sets from the rails may occur, resulting in very large overloads of wheel rims, caused by impacts of wheel sets onto rails. This phenomenon concerns selected resonant and/or very high operating speeds;

(5) At resonant operating speeds, random vertical track irregularities may cause detuning or increasing resonant effects in BTT systems. Time histories of longitudinal normal stresses in the steel beams are affected by high frequency oscillations compared to a smooth track case;

(6) Random vertical track irregularities cause high frequency oscillations with large amplitudes in vertical accelerations of the platform. The TSC condition is mostly unsatisfied, but the crossing level decreases as a span length and a track irregularity grade increase. In the case of a smooth track, the TSC condition is not satisfied just for the shortest bridge (SCB-15). This 
problem can be solved using a thicker ballast layer;

(7) Time-histories of bridge deck accelerations, when vertical track irregularities TI4 exist, are consistent with well-known experimental results which add credibility to the results;

(8) The PCC condition is satisfied at a very good or good level for NTI, TI6, TI5 and TI4 irregularity grades for operating speeds to $300 \mathrm{~km} / \mathrm{h}$;

(9) The SC condition is satisfied for NTI, TI6, TI5 and TI4 irregularity grades for operating speeds to 300 $\mathrm{km} / \mathrm{h}$;

(10) The DC condition is satisfied for NTI, TI6, TI5 and TI4 irregularity grades, but with different values of the safety margin $n_{s} \geq 1.20$;

(11) Objects forming the SCB series-of-types meet all design conditions (SC, DC, TSC, PCC) and can be used for high-speed railways, provided that:

- Random vertical track irregularity grade is the highest (TI6);

- A thicker layer of macadam ballast (ca. $50 \mathrm{~cm}$ ) under a sleeper is applied on the bridge and in the approach zones;

- Operating speeds are $\leq 270 \mathrm{~km} / \mathrm{h}$;

- In reference to SCB-15 and SCB-18 bridges, trains move at extra resonant operation speeds (velocities close to $v_{31}$ and $v_{21}$ are excluded).

\section{Acknowledgments}

The study is supported by the National Centre for Science, Poland as a part of project No. NN5060992 40, realized in the period 2011-2013. This support is gratefully acknowledged.

\section{References}

[1] K.H.C. Wiriyachai, V.K. Gang, Bridge impact due to wheel and track irregularities, ASCE Journal of the Engineering Mechanics Division 108 (4) (1982) 648-666.

[2] X. Lei, N.A. Noda, Analyses of dynamic response of vehicle and track coupling system with random irregularity of track vertical profile, Journal of Sound and Vibration 258 (1) (2002) 147-165.

[3] F.T.K. Au, J.J. Wang, Y.K. Cheung, Impact study of cable stayed railway bridges with random rail irregularities,
Engineering Structures 24 (2002) 529-541.

[4] M. Klasztorny, Dynamics of Beam Bridges under High-Speed Trains, Technical and Scientific Publishing Press, Warsaw, 2005. (in Polish)

[5] M. Podworna, M. Klasztorny, Vertical vibrations of composite bridge/track structure/high-speed train system. Part 2: Physical and mathematical modelling, Bulletin of Polish Academy of Sciences/Technical Sciences 62 (1) (2014) 181-196.

[6] F.T.K. Au, J.J. Wang, Y.K. Cheung, Impact study of cable-stayed bridge under railway traffic using various models, J. Sound Vib. 240 (3) (2001) 447-465.

[7] Q.L. Zhang, A. Vrouwenvelder, J. Wardenier, Numerical simulation of train-bridge interactive dynamics, Comput. Struct. 79 (2001) 1059-1075.

[8] M. Podworna, Vertical vibrations of steel beam bridges induced by trains moving at high speeds, Part 1-Theory, Archives of Civil Engineering 51 (2) (2005) 179-209.

[9] M. Podworna, Vertical vibrations of steel beam bridges induced by trains moving at high speeds, Part 2-Numerical analysis, Archives of Civil Engineering 51 (2) (2005) 211-231

[10] M. Majka, M. Hartnett, Dynamic response of bridges to moving trains: A study on effects of random track irregularities and bridge skewness, Comput. Struct. 87 (2009) 1233-1253.

[11] PN-85/S-10030, Bridge Objects, Loads, 1985. (in Polish)

[12] PN-82/S-10052, Bridge Objects, Steel Structures, Design, 1982. (in Polish)

[13] M. Podworna, M. Klasztorny, Vertical vibrations of composite bridge/track structure/high-speed train system, Part 1: Series-of-types of steel-concrete bridges, Bulletin of Polish Academy of Sciences/Technical Sciences 62 (1) (2014) 165-179.

[14] J. Karlikowski, A. Madaj, W. Wołowicki, Composite Steel-Concrete Bridge Structures, Publisher of Transport and Telecommunication Press, Warsaw, 2007. (in Polish)

[15] M. Podworna, M. Klasztorny, Vertical vibrations of composite bridge/track structure/high-speed train system, Part 3: Deterministic and random vibrations of exemplary system, Bulletin of Polish Academy of Sciences/Technical Sciences 62 (2) (2014) 305-320.

[16] L. Fryba, Dynamics of Railway Bridges, Academia, Praha, 1996.

[17] M.K. Song, H.C. Noh, C.K. Choi, A new three dimensional finite element analysis model of high-speed train-bridge interactions, Engineering Structures 25 (2003) 1611-1626.

[18] F. Lu, J.H. Lin, D. Kennedy, F.W. Williams, An algorithm to study non-stationary random vibrations of vehicle-bridge system, Comput. Struct. 87 (2009) 
177-185.

[19] EN 1990 Eurocode: Basis of Structural Design, Annex A2: Application for Bridges, 1990.

[20] UIC (International Union of Railways) (Draft) Code
776-2, Design Requirements for Rail Bridges Based on Interaction Phenomena between Train, Track, Bridge and in Particular Speed, Paris, France, Union Int. des Chemins de Fer, 2003. 